\title{
A LIFE TRANSCENDENT: IMPACT OF SPIRITUALITY ON LIBERATING INDIAN WOMEN FROM PATRIARCHAL OPPRESSION
}

An Interpretative Phenomenological Analysis

\author{
Sameepta Girdhar \\ Shri Ram School, Aravali \\ DOI: 10.46609/IJSSER.2020.v05i11.010 URL: https://doi.org/10.46609/IJSSER.2020.v05i11.010
}

\begin{abstract}
For a country like India, where female goddesses are worshipped in Indian scriptures that call for the respect for women, it seems paradoxical that it has a deeply-entrenched patriarchal culture. Yet this is the harsh reality: the vast majority of Indian states are patriarchal, whereby women live under male subjugation. One principal force in entrenching the patriarchal culture in Indian society is institutional religions that often justify the denial of agency to women and sanction their oppression. Many Indian women have turned to spirituality, i.e., non-institutional religions, as a means of freeing themselves from patriarchal oppression. Some of these beliefs and practices are derived from the richness and diversity of India's deeply-rooted spiritual beliefs in the deific power of divine souls, saints and yogis. Through this paper, I sought to explore the extent to which women have harnessed their pursuit of spirituality, be it beliefs and practices, as an instrument for them to deal with patriarchal oppression. Through in-depth, one-on-one interviews with Indian women and spiritual leaders, the findings revealed that the pursuit of spirituality can either serve to empower women and genuinely liberate them from patriarchal oppression or enable them to cope with patriarchal oppression. The implication of this study is that the extent of the effectiveness of spirituality as an instrument for improving the quality of life of oppressed women in patriarchal situations is dependent on their expectations and desires to move beyond the patriarchal confines.
\end{abstract}

\section{Introduction}

Despite its celebration of female goddesses who are worshipped in Indian scriptures (Diesel, 1992; Rao et al., 2015), India is also a highly patriarchal country whose oppression of women is systemically entrenched in every sphere of society (Bannerji, 2016). Expected to bear the disproportionate burden of upholding religious, cultural and moral values, Indian women are subjected to restrictive standards of propriety and decency (Moore, 1994). This reality has not 


\section{International Journal of Social Science and Economic Research}

ISSN: $2455-8834$

Volume:05, Issue:11 "November 2020"

only impinged upon their individual freedoms such as the way they dress, their life choices, their lifestyles, and assertion of their opinions, but it has also justified acts committed against them (Bannerji, 2016; Moore, 1995).

What has contributed to the deep-seated nature of this male oppression is the fact that it is sanctioned by traditional religious beliefs and practices (Chowdhury et al., 2013). A number of religious-cultural practices, some of which are quite ancient, are complicit in enabling the abusive treatment of women. They include:

- Dowry murder: The dowry system, which involves the bride family's offering of valuable goods, cash or property to the in-laws as part of the marriage, is the ultimate encapsulation of the patriarchal system, propped up by a combination of economic, social and religious factors (Dalmia \& Lawrence, 2005). Widely practised by Hindus and Muslims, as well as other religions, the dowry system, on paper, constitutes a form of premortem inheritance of the bride by her family (Dalmia \& Lawrence, 2005). India has an alarming trend of dowry-related deaths, in which women are killed and maimed because of dowry disputes (Banerjee, 2013). The National Crime Bureau of India (2017) recorded nearly 7000 dowry-linked deaths. In fact, dowry deaths rose from about 19 per day in 2001 to 21 per day in 2016.

- Female infanticide and feticide: As a result of the dowry system, baby girls impose a tremendous financial burden for the family in rural communities (Rao et al. 2015). Based on the United Nations' unofficial calculations, as many as "200 million females are missing in the world; women who should have been born and grown up, were killed byinfanticide or selective abortion" (Centro de Congressos de Lisboa, 2000).

- Lack of access to professional maternal care. Women, particularly those living in rural communities, have little choice, but to accept family care during their pregnancy and childbirth. Home births account for two-thirds of all deliveries (McLeod, 2020). However, the absence of unhygienic conditions can lead to high rates of maternal mortality: nearly five women die every hour in India from complications developed as a result of childbirth, with heavy blood loss caused by haemorrhage being a major factor (McLeod, 2020; WHO, 2016). Nearly 45,000 mothers die due to causes related to childbirth every year in India which accounts for 17 per cent of such deaths globally, according to the global health body (WHO, 2016).

- Forced suicide: An ancient Hindu tradition called suttee mandates that a widow burns herself to death on her husband's pyre (Jain, 2018). Though it was initially meant to be a voluntary act, a reflection of the woman's courage and heroism in her willingness to sacrifice herself, it later became a forced practice (Jain, 2018). 


\section{International Journal of Social Science and Economic Research}

ISSN: $2455-8834$

Volume:05, Issue:11 "November 2020"

Given the endorsement of male oppression against women in these religions, it is perhaps little wonder that patriarchal oppression also runs deep in a majority of Indian households. Patriarchy, in the most basic sense, is defined as the male domination of women in power relationships (Millett, 1969). The majority of Indian states are patriarchal, whereby women lead lives that are determined by gender stereotypes through every phase of their existence. From being bullied daughters and sisters in their families of origin to becoming abused wives and daughters-in-laws, women are afflicted by male oppression in all forms of physical and emotional abuse. Despite 50 years of progress in human rights, India's struggle with gender inequality is evidenced by its appalling ranking of 136th out of 186 countries on United National Development Programme's (UNDP, 2014) Gender Inequality Index (GII). The UN Development Report identified women as one of India's most marginalised groups (UNDP, 2014).

In the face of male-dominated religious institutions, with their promotion of oppressive interpretations of religious texts, many Indian women have turned to spirituality as a means of coping with patriarchal oppression. At this juncture, it is important to highlight the definitions of 'religion' and 'spirituality', as adopted within the context of this paper. According to Bryant (2007), 'religion', with its extrinsic focus, places an emphasis on the constructed behaviours of group membership, coherent theology, belief systems, and worship (p. 835). 'Spirituality', on the other hand, with its intrinsic perspective, is centred upon an individual process, experience, and state of being in search of connection with something transcending human existence (Passalacqua \& Cervantes, 2008, p. 224).

Therefore, this paper sought to address the impact of spirituality on a person's psyche and actions (Berkel et al., 2004; Bryant, 2007; Fukuyama \& Sevig, 1999), rather than outward adherence to norms and practices. Through the in-depth analysis of the narratives of Indian women and spiritual leaders, it is hoped that this research paper would offer a penetrating glimpse into how the practice of self-defined spirituality could 'liberate' women from the toll of patriarchy in India.

\section{Description of Research Study}

\section{Research Aim and Research Approach}

The aim of this research study was to examine the extent to which Delhi women's selfconceptualisations of spirituality enable them to cope with patriarchal oppression by exploring the lived experiences of Indian women and spiritual leaders. With its focus on a detailed examination of the meanings that particular experiences, events, states hold for participants (Pietkiewicz \& Smith, 2014), the Interpretative Phenomenological Analysis (IPA) approach was highly appropriate for this research study. This approach that strives to capture the collective 


\section{International Journal of Social Science and Economic Research}

ISSN: $2455-8834$

Volume:05, Issue:11 "November 2020"

experiences of participants, while engaging in in-depth analyses is founded upon three premises "phenomenology, hermeneutics, and idiography" (Pietkiewicz \& Smith, 2014, p. 8):

- Phenomenology: how people make sense of their particular experience from their point of view (Pietkiewicz \& Smith, 2014).

- Hermeneutics: how a researcher interprets the interviewees' perceptions and interpretations of their phenomena, thus creating a rich and complex double-layered interpretation (Smith \& Osborn, 2008).

- Idiography: how the in-depth examination of the individual experiences culminates into an overall understanding of the shared phenomenon (Pietkiewicz \& Smith, 2014).

The IPA approach thus challenged me to stand in the shoes of my interviewees, as they shared their narratives of how they used spirituality to deal with their experiences of patriarchal oppression and come up with my interpretations of the common patterns that emerged from their words. The findings would thus show the extent to which spirituality could be used as a useful tool for Indian women to cope with patriarchal oppression in India.

\section{Sampling}

Two categories of interviewees were targeted for this research study: Indian women with experiences of patriarchal oppression and spiritual experts from Delhi. By using purposive sampling, I chose Indian women between the ages 25 and 50, who would have experienced the households of their families of origin and their in-laws. Moreover, they had to have experienced patriarchal oppression in the hands of their fathers and husbands. Finally, they had turned to some kind of non-traditional spirituality as a means for them to deal with patriarchal oppression.

By reaching out to various women from different spiritual organisations across Delhi NCR, along with referrals from acquaintances, invitations were sent out to women for participation in a semi-structured phone interview (see Appendix A). Ultimately, three women, ranging in age from 25-50, whose socio-economic strata extended from low to high, participated in the interviews.

Furthermore, I also contacted spiritual leaders via emails and text messages. As with the women, they too received a formal invitation to take part in an interview (see Appendix A). The interviews of twospiritual leaders provided a broader perspective of the women's practices of their spirituality, as these leaders had access to large groups of women who would congregate at their centres for spiritual communion and support. 


\section{International Journal of Social Science and Economic Research}

ISSN: $2455-8834$

Volume:05, Issue:11 "November 2020"

The combination of the personal experiences of women and the broad-picture observations of the spiritual leaders thus allowed for the investigation of the extent to which spirituality helped Indian women to cope with the oppression.

\section{Data Collection}

In-depth, individual telephone interviews in a semi-structured format were conducted with the interviewees living in Delhi-NCR. The interview questionnaire was sent to interviewees in advance in order to give them time to reflect about their responses prior to the interview (see Appendix B). This was to ensure the likelihood of success in eliciting well-thought-out responses without taking up too much of the interviewees' time.

The content of the pre-formulated interview questions was derived from a review of the mentoring literature and the analysis of content from a focus sample on mentoring. With regards to the women, the questions revolved around their experiences with patriarchal oppression and its impact on their well-being, followed by their use of coping strategies through spirituality, as well as the impact. In the case of spiritual experts, they were asked to consider how the beliefs and practices of spirituality have enabled Indian women to deal with patriarchal oppression.

The interviews that were conducted during the month of May 2020 lasted 40-60 minutes. With the permission of the interviewees, all the interviews were recorded for transcription and analysis purposes. The interviewees were informed accordingly.

\section{Data Analysis}

Thematic analysis was conducted based on the practical guidelines provided by Pietkiewicz and Smith (2014). It is recommended that researchers totally immerse themselves in the data or, in other words, try to step into the interviewees' shoes as far as possible. Hence, I analysed the interviews of these women accordingly. By reading and re-reading the transcripts to code the relevant text from each interviewee, followed by the identification of common patterns, I could identify emerging themes. Finally, by clustering these emerging themes, I was then able to identify the final set of themes presented in the "Discussion of Themes".

\section{Findings}

In this chapter, through the discussion of the themes, supported by the narratives of the interviewees, I will try to show the extent to which Indian women's self-conceptualisations of spirituality have helped them to cope with patriarchal oppression. We begin with a "Description of the Interviewees" (see Tables 1 and 2). 
The women interviewees were aged 35 and above. All of them were born and brought up in an Indian society. Keeping these factors in mind, each of them has had a significant amount of life experiences as a daughter, a wife, a daughter-in-law, or as a mother. While one of the interviewees was divorced, the other two who were significant older in age - seven and 14 years, respectively, were still currently married. This raises the implication that the older women interviewees could have adopted a more traditional and conservative stance of their situation. As they belonged to a generation of women living under extremely narrow societal constraints, they might not feel sufficiently empowered enough to leave their oppressive marriage.

Another notable preliminary observation about the interviewees is that the older interviewees who were still married had been practising spirituality since childhood. Both of them were born and brought up in spiritual households, which means that they had been greatly influenced by their families of origin. The divorced interviewee, on the other hand, had been practising spirituality for only 11 years, i.e., as an adult. At the most basic level, we can surmise that the long-term engagement in spirituality from one's childhood years would lead one to apply spirituality in a way that is different from someone who practises spirituality as an adult.

Table 1

Description of Women Interviewees

\begin{tabular}{|l|l|l|l|}
\hline $\begin{array}{l}\text { Name } \\
\text { (pseudonyms) }\end{array}$ & Age & $\begin{array}{l}\text { Marital } \\
\text { status }\end{array}$ & $\begin{array}{l}\text { practice of spirituality } \\
\text { (years) }\end{array}$ \\
\hline Maya & 35 & Divorced & 11 \\
\hline Riya & 49 & married & Since childhood \\
\hline Niki & 42 & married & Since childhood \\
\hline
\end{tabular}

The two spiritual experts interviewed belonged to two different spiritual groups. While one of the groups focuses on chanting and connecting with nature as their means of spirituality, the other follows a more traditional Indian spiritual approach such as attending Satsangs ("spiritual congregations"). As a result of these practices, they were often in contact with informal congregations of women. 
While Rakesh had been practising spirituality for 30 years, Naina had been engaged in spirituality since childhood. Therefore, both spiritual experts had been deeply immersed in the spiritual practice for decades.

Table 2

Description of Spiritual Experts

\begin{tabular}{|l|l|l|}
\hline Name (pseudonyms) & Age & practice of spirituality (years) \\
\hline Rakesh & 66 & 30 \\
\hline Naina & 48 & Since childhood \\
\hline
\end{tabular}

\section{Discussion of Themes}

In the sections that follow, these themes that chart the trajectory of our understanding of the effectiveness of spirituality as a tool for dealing with patriarchal oppression will be discussed:

- Patriarchal Oppression as Trigger for Quest for Spirituality;

- Spirituality as an Instrument of Freedom from Patriarchal Oppression; and

- Spirituality as a Double-Edged Sword in Transcending Patriarchal Oppression.

\section{Theme 1: Patriarchal Oppression as Trigger for Turning to Spirituality}

This theme encapsulates the women interviewees' experiences of moving from one patriarchal household to another from birth to marriage. The cumulative impact of their suffering under these circumstances shows how their experiences of patriarchal oppression served as an impetus to spur them towards spirituality.

Both Maya and Riya provided vivid narratives of the dominance of male members in their families of origin in which they were deprived of any freedom of making decisions and the options to pursue an alternative life than the conventional one typically expected of women: 


\section{International Journal of Social Science and Economic Research}

ISSN: $2455-8834$

Volume:05, Issue:11 "November 2020"

I have experienced male dominance from an early age in my life. All decisions were taken by my father for me. Be it who I had to marry or what I could or could not do, only his vision of what we each should be was followed. (Maya)

Although I belong to a 'modern family' according to Indian society, being the daughter of the home, decisions were made for me since I was born. I was told my studies did not hold as much importance as getting married was. (Riya)

Typically, the dominant male member of the family was the father whose authority was unchallenged by anyone else in the household:

I have a father with rigid beliefs. He was not very flexible. Everyone in the family had to abide by his principles. He often got angry when I tried disagreeing with any of his views. My mother made excuses for my father's bad temper and encouraged me to accept him as he was. (Maya)

These statements resonate with the existing discourse on the Indian culture about patriarchy in Indian households. The Indian family is, by and large, patriarchal in structure (Kapadia, 1982). In a patriarchal family set up, all-male members, that is, husband, elder brother, and father, perform duties like decision-making for the rest of the family purportedly for the physical and moral protection of the female members (Kapadia, 1982). As such, the perspectives of the female members of the household are rendered unimportant. Such a reality, perpetuated from the beginning of one's life, both through direct experience and observations of the women around them, cannot possibly must have left an indelible impression on the women.

Furthermore, these interviewees also spoke about not getting as much attention or being treated with the same consideration as the males in the family:

I feel my brother was always given more love growing up... I just wish I got loved the same way he did. (Riya)

I belong to a large family with many siblings. When we had competitions in school, I was never given the same appreciation as my brothers... even when I scored well in an exam. It always made me feel as if I was not good enough. (Niki)

Living in such an environment in which their self-worth was constantly ignored or even undermined would likely exert a negative psychological impact on their sense of self-worth and evaluation. They were never made to feel loved or validated for their achievements. In fact, this is considered to be common plight of girls who are simply dismissed as unimportant as they will be married out of the family and perform "inherit their mother's domestic chores". This is little 
International Journal of Social Science and Economic Research

ISSN: 2455-8834

Volume:05, Issue:11 "November 2020"

wonder that "low self-esteem and self-worth" are prevalent in Indian society (Rao et al., 2015, p. S212).

What is so tragically unjust about this situation for females is that this bias towards males in the household is part and parcel of the patrilineal practice - the fact that only the male issue could hold property and carry on his father's lineage after the latter's death (Madan, 2000, p. 315)Therefore, the importance given to male issues in a family is entrenched within the sociocultural makeup of the Hindu society, as with many other patriarchal societies (Madan, 2000, p. 315). This unquestioned entitlement that favours male progeny over females thus renders the latter undesirable and vulnerable in the eyes of their family, more a burden than a joy.

Against such a backdrop, it is only logical that females are pressured to get married early. In fact, all three interviewees spoke about this pressure of an early marriage.

I got married at an early age of 24 as I was pressured a lot by my family. I most definitely did not want to get married at such an early age. I didn't even know the boy, it was an arranged marriage. (Maya)

My parents never had any restrictions with getting educated or having a job, but they always told me to get married and get settled down.. They said I could continue working at my in-laws'. (Riya)

The pressure for the women to get married is clearly a reflection of the limiting patriarchal conception of the potential of female women. Hindu marriage is regarded as a means of establishing a relationship between two families. Free intermixing between two sexes is a taboo. Thus, most marriages are arranged by parents or relatives, even in the educated class. Children are expected to accept their parents' decision with respect to marriage unconditionally, with extra-marital relationships, separations, and remarriage looked down upon (Sharma et al., 2013).

This essentially means that the women would be compelled to live with the adverse consequences of these decisions that had been imposed upon them. Within the predominantly patriarchal context of India, a woman's life fundamentally revolves around being a wife and mother. In fact, the 'unmarried' status in India is a stigma, particularly for females (Sharma et al., 2013). The fate of a female in Indian society is best encapsulated in prescriptions: "She should do nothing independently even in her own house. In childhood subject to her father, in youth to her husband, and when her husband is dead to her sons. She should never enjoy independence" (as qtd. in Basham, 1967, p. 182). 


\section{International Journal of Social Science and Economic Research}

ISSN: $2455-8834$

Volume:05, Issue:11 "November 2020"

Unfortunately, for the interviewees in the research study, their experiences of patriarchal oppression further escalated when they entered their in-laws' households after getting married, as they became completely imprisoned in the gender-stereotypical roles. Essentially regarded as a nobody 'outsider', they were bullied by their husbands and rendered powerless in maledominated household:

I wasn't allowed to work after marriage and had to handle the children on my own. My husband had a habit of controlling every single thing I did... He also used to attack me for my weight, which led to my body image issues... He also used to get drunk and extremely aggressive. Screaming and violently abusing me (verbally) was something he used to do in order to establish himself as an authoritative figure. (Niki)

When all the other members of the family sat in the living room and discussed the important major decisions of the family, I, as a woman, did not have any say in these decisions. I was constantly treated as an outsider. (Riya)

Worse still, the women in these households often reinforce these oppressive rules, inflicting upon their daughters-in-law the same suffering to which they are subjected, thus highlighting how these dysfunctional patriarchal norms are transmitted from one generation of women to another in a tragic vicious circle:

I remember being bluntly told to bear a child and stay at home. I was told what [my mother-inlaw] had to do after that and what kind of a mother I was to become. A grim set of rules were imposed on me. (Riya)

At my in-laws', patriarchy was not only imposed, but also promoted by my own mother in law... her being a woman, can you believe it?! I wasn't allowed to go anywhere, make my own decisions or do anything of my choice. Others' decisions were imposed on me. I was told what to do, and how my day was supposed to be spent. I was told things like 'you belong in the kitchen, women are supposed to be religious and complete the religious practices...' (Maya)

The process of being constantly oppressed took a toll on the interviewees' mental health:

Because of my experience, I lost all of my confidence and felt dependent and low all the time. I decided to eventually get out of the horrifying situation as it took a major negative toll on me. (Maya)

To appreciate how hard Maya's life had been in her former husband's household, one has to know how much a divorced woman is repudiated in an Indian society. As Maya stated, "Being a 
International Journal of Social Science and Economic Research

ISSN: 2455-8834

Volume:05, Issue:11 "November 2020"

divorced single woman is not easy. I have to hear many cheap comments just because I am single." Community disapproval is stronger for divorced women than it is for divorced men (Lessinger, 2002). This is no different in India's double-standard society, where being single is far more acceptable for men than it is for women (Sharma et al., 2013). When a woman is not married, it is assumed that there is something wrong with her: it is presumed that she may be very difficult to get along with, thus leading to her 'single' status (Sharma et al., 2013).

Although Maya decided to leave her then-husband, her decision is more the exception than the norm (Sharma et al., 2013).Divorce is not always an option. Instead, many Indian women, such as the other interviewees, opt to remain within their marriages, no matter how hard it is:

I felt as though I was stuck in life, in a dilemma not knowing what to do. But whenever things got difficult I chose to pray to god for strength. Giving up on the relationship did not seem like a solution for me. (Niki)

As will be discussed later, spirituality will play a critical role for all of the interviewees to enable them to deal with the effects of patriarchy.

\section{Theme 2: Spirituality as an Instrument of Freedom from Patriarchal Oppression}

Unlike traditional religions with its prescribed rules and norms, the spirituality that the women interviewees subscribed to contains a hodge-podge of what they considered to be helpful for them to connect with what a "higher consciousness" is, as Niki put it. While some aspects of this spirituality are linked to spiritual groups, others are far more individualised. One can see how each interviewee had pursued their own version of spirituality and found solace in it in their own ways:

I was strongly impacted by the book, The Secret. The book talks about the law of attraction the idea that what you focus on grows. You start believing it once you experience it yourself. It felt as if the book defined my life and I found it extremely relatable. It completely changed my perspective as to how I viewed people and situations. (Niki)

The very belief of "self-love" is what made her beliefs different from the other interviewees. Niki believed in prioritising her mental health, while focusing on being a good human being. This exercise is what helped her to attain the freedom that she was deprived of in her life.

In the case of Riya, her pursuit of spirituality was more group-oriented, as it involved connecting with a spiritual group that follows a comprehensive series of established beliefs and practices built upon ancient Indian traditions: 


\section{International Journal of Social Science and Economic Research}

ISSN: $2455-8834$

Volume:05, Issue:11 "November 2020"

I felt as though praying was the best remedy for me, hoping my life would come back to the right track. Moreover, I very strongly believe in my guru. His guidance helped sort my life out. Rather than struggling with the way of life, I moved my focus to satsang which helped bring me tranquility. Satsang is fellowship with others with similar spiritual aspirations and fellowship with God.

One could surmise that the advantage of pursuing a more group-oriented spirituality helped Riya by offering her a family of 'choice' that serves as an important refuge for her.

Despite these differences in the interviewees' approaches towards spirituality, there are common characteristics that unify them: their engagement in the practices to promote "acceptance", "forgiveness" and "gratitude". All of these practices are highly interrelated as they do call for a state of mind to enable one to transcend the adverse effects of patriarchal oppression. While gratitude refers to the condition of being unconditionally thankful for being alive, it is also characterised by the willingness to accept both the positive and negative circumstances in life, which often entails forgiving others:

Acceptance and loving people the way they are is something that I have tried practising. Everyone's perspective is different. Everyone has got their own choices and opinion, hence, we should respect them. I have tried focusing on the positive aspect of my relationship and learned to forgive... I cannot think of any task, not even menial daily tasks, without praying, thanking shukrana (sense of gratitude) and remembering the higher conscience. (Riya)

Gratitude and thankfulness became my strongest belief. Counting your blessings is extremely important. (Niki)

By adopting such a stance, the interviewees were able to feel empowered and even hopeful about their circumstances:

The energy makes me feel protected. It has empowered me whenever I was reminded of bad times. Spirituality gave me strength to deal with situations at home. (Riya)

It keeps you going with a consistent set of mind. The 'energy' always made me feel protected. (Niki)

These interviewees' statements echo Coyle's (2002) definition of spirituality as something that gives hope, that strengthens the individual, and something to rely on. One can thus see how spirituality can put the interviewees into a state of mind to enable them to cope with the hardships. 


\section{International Journal of Social Science and Economic Research}

ISSN: $2455-8834$

Volume:05, Issue:11 "November 2020"

In delving into the power of these positive dynamics of spirituality, which can enable it to even overturn the constant toll of abuse and exploitation, it is important to recognise its comprehensive influence on an individual's development, identity, belief system and cultural paradigm (Berkel et al., 2004; Fukuyama \& Sevig, 1999). In challenging the people to find out one's "purpose of life and self", as Niki put it, this quest of spirituality also involves what Rakesh, a spirituality expert, explained as:

...connecting with your own spirit and other spirits that include anything living and has a soul and purpose in your surroundings. From a godly point of view - connecting with the higher power. In spirituality, before god, realisation.

Fundamentally, spirituality connects every relationship and sphere of life and transforms it by concentrating it into one's willingness to achieve self-realisation. Based on the emphasis on "connecting" with all, it thereby encourages individuals to accept their life situations and others, by asserting control over their own lives with positive thoughts, thus transcending their sense of powerlessness (Hungelmann et al., 1996).

The spotlight is thus placed on the control of the inner mind, not on the external circumstances. Although most of the women interviewees remain 'imprisoned' in their patriarchal households, they felt freed in their minds through their practice of spirituality. Thus, thanks to spirituality that influences their well-being through their thoughts and behavior (Hadzic, 2011), they are still able to feel empowered.

This empowering of the inner self is no small matter. Even in the case of Maya who left her marriage, she had had to turn to spirituality to repair the damage inflicted on her inner being:

I had grown up with a belief that you can never flourish if you wish bad for somebody else.. but because of my experience with patriarchy and oppression, I became a very sour and bitter person, and started wishing bad upon people who made me go through it... it shook my entire belief system. As I became a bitter person, I realised how toxic it was...

In a quest to return to her values, Maya turned to spirituality in order to restore her positive sense of self:

Spirituality brought me back to my path, it made me realise the importance of the positive energy around me. Most importantly, I had to sacrifice my belief of "self-love" which I strongly felt for. That is when I turned to spiritual means and decided to step back and give as much importance to my well-being. 
International Journal of Social Science and Economic Research

ISSN: 2455-8834

Volume:05, Issue:11 "November 2020"

Spirituality allowed Maya to let go of her bitterness and revived a positive sense of self so that she could deal constructively with her situation.

\section{Theme 3: Spirituality as Double-Edged Sword in 'Transcending' Patriarchal Oppression}

While the previous theme illuminates the clear benefits of spirituality in empowering Indian women to cope with patriarchal oppression, the third and last theme points to an ambivalent element of spirituality - its role in enabling the perpetuation of patriarchal oppression. In a nutshell, spirituality can be construed to help Niki and Riya put up with their husband's abusive behaviour and submit to it in a passive way:

I strongly believe in the power of sumiran ("praying"). Whatever disagreements or disturbing thoughts, I have in mind to get settled by remembering god. (Riya)

It has given me strength whenever I was reminded of the bad times. (Niki)

Though these statements suggest that their practice of spirituality had brought them peace of mind or strengthened their capacity for dealing with suffering, it seemed to have come at a significant price of self-realisation and the reinforcement of a negative social situation. By acquiescing to their circumstances, these interviewees also appeared to be living in denial of the immutable truth that they were being oppressed. One could say that their spirituality had provided them with a perfect cloak for their denial of the ugliness of their existence.

Moreover, these two interviewees, in their pursuit of spirituality, were not alone in embracing these beliefs without question. Spiritual leaders and spiritual experts interviewed for this research study also promulgated beliefs that do not challenge the patriarchal oppression:

A spiritual person is always forgiving in nature. They see an opportunity in every difficulty rather than the opposite. This gives them an unshakeable spirit. No problem is big enough to make their spirit unstable. (Rakesh)

One surrenders themselves to this almighty and accepts situations the way they are. Acceptance frees them to use their energy wisely rather than deplete it with unhealthy attitudes and endless questions that only add to their pain. (Naina)

Both of these quotes clearly put a positive spin on passive surrender to patriarchal oppression in their conceptualisation of spirituality. In fact, Naina even pointed out that at her spirituality sessions, where oppressed women come together to show support for one another, there is no attempt to push women towards any position, but rather to acknowledge their decisions. It would seem that, as a spirituality leader, more than a woman, her spirituality does not allow her to adopt 


\section{International Journal of Social Science and Economic Research}

ISSN: $2455-8834$

Volume:05, Issue:11 "November 2020"

a definite stance against the patriarchal oppression and victimising effects. This makes me wonder about the limitations of spirituality, as it is practised within the institutional and systemic constraints of society, in challenging this kind of thinking.

Against this backdrop, it is thus important to consider the example of Maya who actually made the courageous decision of breaking free from the shackles that held her back. In her case, her practice of spirituality led her to an important breakthrough:

I realised the importance of loving oneself through spirituality. Although it does not mean I have to be selfish and put myself first, but just simply loving myself. Once this realisation struck me, I knew I had to drag myself out and start fresh.

Unlike the others whose conception of 'self-love' achieved through spirituality was not to be encumbered by the unhappy thoughts arisen from one's lives, even at the expense of one's selfrealisation, Maya's attainment of 'self-love' through spirituality led to the recognition of her selfworth. She could see that her growth was stunted because of the mindset of the people surrounding her. Since then, she has gone on to lead a healthier life.

I am in a very happy place in life right now. I have learned to love myself and that makes me feel empowered. Most importantly, while acting these actions, I can feel the effect of my actions on the other person. I can feel the other person and myself heal. It makes me feel stronger as a person.

Maya, along with the other women interviewees, chose to embark on a journey of spirituality to make herself feel liberated. However, the only difference between her pursuit of spirituality, as compared to the other women, was how she chose to act upon her spiritual beliefs in her life.

\section{Conclusion}

What do our findings tell us about the effectiveness of spirituality in enabling women to cope with patriarchal oppression in India? Well, the answer is, by no means, straightforward. You can say it depends on whom you speak to and how he/she interprets these findings. As Themes 2 and 3 have shown, spirituality as a factor can produce both negative and positive outcomes with opposing implications. While the spiritual beliefs of Maya led to her courageous escape from patriarchal oppression, spirituality as practiced by the other women interviewees got them to stay firmly ensconced within it. Although spirituality seemed to have empowered them to cope with their circumstances in a more empowered situation, their opportunity to fully love themselves was severely circumscribed. To top it off, spiritual experts and leaders interviewed in this 


\section{International Journal of Social Science and Economic Research}

ISSN: $2455-8834$

Volume:05, Issue:11 "November 2020"

research study also appeared to advocate for a version of spirituality that encourages passive acquiescence to these circumstances.

Based on these two seemingly irreconcilable outcomes, one can see that spirituality is a powerful tool that can produce definite outcomes. Depending on the practitioner, it can either give them the impetus to thrust them out of patriarchal oppression or give them the wherewithal to bear the sufferings. Given the fact that so-called spirituality leaders and experts are still occupying a space that does not unequivocally turn women away from the ills of patriarchal oppression, it would seem that changes in these areas would need to be done so that individual women can receive the necessary support for them to liberate themselves from the shackles of patriarchal oppression.

\section{Reference}

Bannerji, H. (2016). Patriarchy in the era of neoliberalism: The case of India. Social Scientist, 44(3/4), 3-27. https://www.jstor.org/stable/24890241

Bannerji, P. (2016). Dowry in 21st-century India: The sociocultural face of exploitation. Trauma Violence Abuse, 15(1), 34-40. https://doi.org/10.1177/1524838013496334.

Berkel, L. A., Vandiver, B. J., \& Bahaner, A. D. (2004). Gender role attitudes, religion, and spirituality as predictors of domestic violence attitudes in white college students. Journal of College Student Development, 45(2), 119-133.

Bryant, A. N. (2007). Gender Differences in Spiritual Development During the College Years. Sex roles $56(11), 835-846$.

Bumiller, E. (1991). May you be the mother of a hundred sons: A journey among the women of India. Penguin Books.

Chowdhury, A., \& Patnaik, M. M. (2013). Understanding the Indian family tree: The gender perspective. International Journal of Multidisciplinary Management Studies, 3, 57-67

Coyle, J. (2002). Spirituality and health: Towards a framework for exploring the relationship between spirituality and health.Journal of Advanced Nursing, 37, 589-597.

Dalmia, S., \& Pareena, G. L. (2005). The institution of dowry in India: Why it continues to prevail. The Journal of Developing Areas, 38(2), 71-93. 


\section{International Journal of Social Science and Economic Research}

ISSN: $2455-8834$

Volume:05, Issue:11 "November 2020"

Diesel, A. (1992). The worship and iconography of the worship and iconography of the Hindu in Natal. Journal for the Study of Religion, 5(2), 3-30. https://www.jstor.org/stable/24763966

Fukuyama, M. A., \& Sevig, T. D. (1999). Integrating spirituality into multicultural counseling (Vol. 13). Sage Publications, Inc.

Hadzic, M. (2011). Spirituality and mental health: Current research and future directions. Journal of Spirituality in Mental Health, 13(4), 223-235.

Hungelmann, J., Kenkel-Rossi, E., Klassen, L. \& Stollenwerk, R. (1996). Focus on spiritual well-being: Harmonious interconnectedness of mind-body-spirit-Use of the JAREL Spiritual Well-Being Scale.Geriatric Nursing, 17, 262-266.

Jain, R. (2018). The history behind 'sati': A banned funeral custom in India. Culture Trip. https://theculturetrip.com/asia/india/articles/the-dark-history-behind-sati-a-bannedfuneral-custom-in-india/

Madan, G. (2000). Indian social problems (Vol. 2): Social disorganization and reconstruction. Allied Publishers Private Limited.

McLeod, J. (2020). Modern India: Understanding modern nations. ABC-CLIO.

Millet, K. (1969). Sexual politics. Granada Publishing.

Moore, E. P. (1994). Law's patriarchy in India. In M. Lazarus-Black \& S. F. Hirsch (Eds.), Contested states: Law, hegemony and resistance (pp. 89-117). Routledge.

Nayar, U. S. (2004). Womanhood and spirituality: A journey between transcendence and tradition. The Indian Journal of Social Work, 65, 584-595.

The National Crime Bureau of India. (2017). Crime in India 2017.https://ncrb.gov.in/en/crimeindia-2017-0

Passalacqua, S. \& Cervantes, J. M. (2008). Understanding gender and culture within the context of spirituality: Implications for counselors. Counseling and Values, 52(3), 224-239.

Pietkiewicz, I., \& Smith, J. A. (2014). A practical guide to using Interpretative Phenomenological Analysis in qualitative research psychology, Psychological Journal, 20(1), 7-14. 
International Journal of Social Science and Economic Research

ISSN: 2455-8834

Volume:05, Issue:11 "November 2020"

Rao, G. P., Vidya, K. L., \& Sriramya, V. (2015). The Indian "girl" psychology: A perspective. Indian Journal of Psychiatry, 57(Suppl 2), S212-S215.

Sharma, I., Pandit, B., Pathak, A., \& Sharma, R. (2013). Hinduism, marriage and mental illness. Indian Journal of Psychiatry, 55(Suppl 2), S243-S249.

United Nations Development Programme. (2014). Human development report 2015: Work for human development. http://hdr.undp.org/en/composite/GII

World Health Organization (WHO, 2016). World health statistics 2016: Monitoring health for the SDGs (sustainable development goals). Author.

https://www.who.int/gho/publications/world_health_statistics/2016/Annex_B/en/ 